\title{
離散時間 $\mathcal{H}_{2}$ 最適制御問題に対する精度保証付き計算*
}

\author{
管野 政明 $\dagger$. 内山 裕貴
}

\author{
Guaranteed Accuracy Computation \\ for Discrete-time $\mathcal{H}_{2}$ Optimal Control*
}

Masaaki KAnNo ${ }^{\dagger}$, Yuki UCHIYAMA ${ }^{\ddagger}$ and Shinji HARA ${ }^{\ddagger}$

\section{1.はじめに}

著者らは，数式処理と区間演算を適切に組み合わせて 構成されるハイブリッド精度保証付き計算アルゴリズム が，ある種の制御問題の精度保証付き計算に対して有効 であることを示している[1-3]. しかし，これらはすべて 連続時間系に対するもので，離散時間系に対して同様の アプローチが有効であるかは明らかではない.

連続時間の結果が得られている場合，離散時間の結果 を得るアプローチの一つとして，与えられた離散時間系 を双一次変換を用いて連続時間系に変換し，連続時間に 対するアルゴリズムを用いて解を求め，それを再び双一 次変換で離散時間領域へ戻すという手法が考えられる。 しかしながら, $\mathcal{H}_{2}$ ノルムは双一次変換で保存されない ため，このアプローチを離散時間 $\mathcal{H}_{2}$ 制御問題に直接適 用することはできない. また，離散時間領域内での計算 のみで精度保証付き計算を実現することは原理的には可 能であるが，実用的な精度保証付きアルゴリズムの構築 が容易でない，その理由は，連続時間系の場合に成功し ていた，通常の数值計算と精度保証付き計算を組み合わ せる高速計算アプローチ [5]を，離散時間系に対して実 現することが難しいからである.

そこで本速報では，双一次変換が有効に機能する部分 に対してはそれを適用することにより，連続時間の効率 的な精度保証付き多項式スペクトル分解（正規化既約分 解）アルゴリズムを利用し，それ以外の部分は離散時間 領域で計算を行うという，離散・連続『ハイブリッド』 な精度保証アプローチを提案する (Fig. 1 参照)。

* 原稿受付 2007 年 6 月 15 日

$\dagger$ CREST, 科学技術振興機構 CREST, Japan Science and Technology Agency; 4-1-8, Honcho, Kawaguchishi, Saitama 332-0012, JAPAN

‡東京大学 大学院 情報理工学系研究科 Graduate School of Information Science and Technology, The University of Tokyo; 7-3-1, Hongo, Bunkyo-ku, Tokyo 113-8656, JAPAN

Key Words: discrete time $\mathcal{H}_{2}$ control, guaranteed accuracy computation, bilinear-transformation.

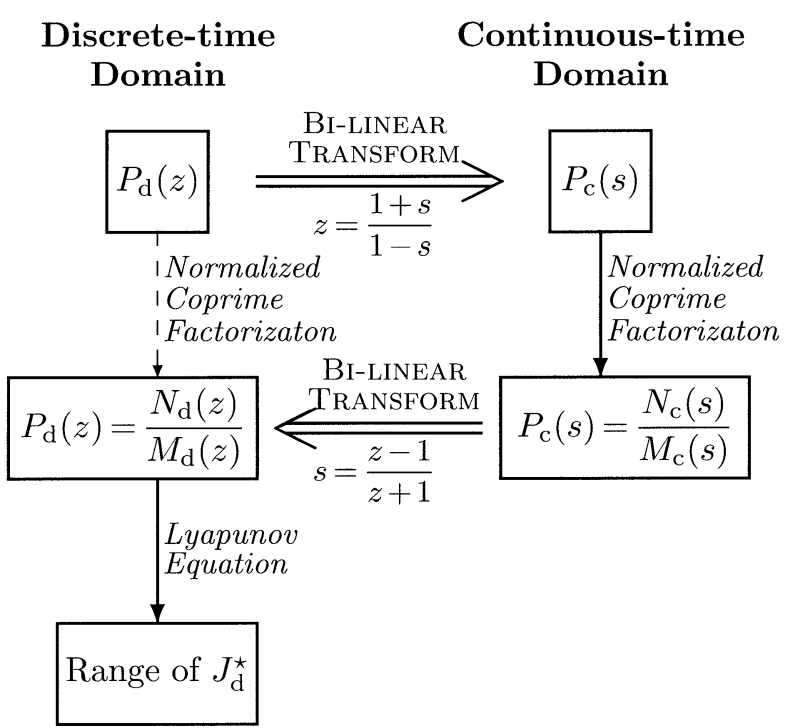

Fig. 1 Hybrid approach to discrete-time guaranteed accuracy computation

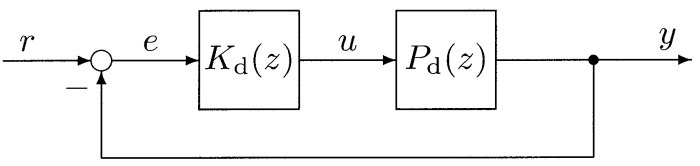

Fig. 2 Unity feedback tracking system

なお，本速報では以下，離散時間に対応する伝達関数・ 多項式等には添え字 $\mathrm{d}$ をつけ，連続時間のものには $\mathrm{c}$ つけて表記する。

\section{2. 離散時間 $\mathcal{H}_{2}$ 最適追従性能：問題設定}

本速報では，離散時間 $\mathcal{H}_{2}$ 制御問題の一つとして, [1] で考慮した $\mathcal{H}_{2}$ 最適追従制御問題の離散時間系版を取り 上げ，その最適性能值の精度保証付き計算を考える。な お, さまざまな $\mathcal{H}_{2}$ 最適制御問題も, 正規化既約分解を 用いることにより解くことが可能であり, 本速報の手法 の適用範囲は広いと考えられる。

Fig. 2 において, $P_{\mathrm{d}}(z)$ は一入力一出力の線形な離散時 間制御対象で, $K_{\mathrm{d}}(z)$ は設計される制御器とする. $r[k]$, 
$u[k], y[k], e[k]:=r[k]-y[k]$ はそれぞれ参照信号, 制御 入力, プラント出力, 偏差信号である. また, 参照信号 は単位ステップ信号とする. 初期状態零の仮定のもと,

$$
J_{\mathrm{d}}:=\sum_{k=0}^{\infty}\left(|e[k]|^{2}+|u[k]|^{2}\right)
$$

で表わされる 2 次形式評価関数を用いる。このとき，

$$
J_{\mathrm{d}}^{\star}=\inf _{K_{\mathrm{d}} \text { stabilizing }} J_{\mathrm{d}}
$$

を求める問題を考える。ここで, 連続時間の場合 [1] と 同様， $P_{\mathrm{d}}(z)$ に対して以下の仮定をおく. (1) 積分器が $P_{\mathrm{d}}$ に一つ含まれていて，それを除くと $P_{\mathrm{d}}$ は安定である. (2) $P_{\mathrm{d}}$ は $z=1$ に零点をもたない.このとき， $J_{\mathrm{d}}^{\star}$ は以下 のように表現できる。なお，証明は連続時間系の場合と ほぼ同様であるので，紙面の都合上省略する。

【定理 1】 $P_{\mathrm{d}}(z)=N_{\mathrm{d}}(z) / M_{\mathrm{d}}(z)$ を $P_{\mathrm{d}}$ の正規化既約 分解とする ${ }^{1}$.このとき, 以下が成立する.

$$
J_{\mathrm{d}}^{\star}=\left\|\left[N_{\mathrm{d}}(z)-N_{\mathrm{d}}(1) M_{\mathrm{d}}(z)\right] \frac{1}{z-1}\right\|_{2}^{2}
$$

この結果は, $J_{\mathrm{d}}^{\star}$ を求めるためには以下の二つの手続 きを行えばよいことを示している。

- $P_{\mathrm{d}}(z)$ の正規化既約分解を求める.

- $N_{\mathrm{d}}(z), M_{\mathrm{d}}(z)$ の状態空間表現を用いて, Lyapunov 方程式を解いて，(1) 式の $\mathcal{H}_{2}$ ノルムを計算する.

次節にて, 上記の二つのことが精度保証付きで計算可 能であることを示す.

\section{3. 最適性能值の精度保証付き計算}

\section{1 連続時間多項式スペクトル分解を用いた離 散時間の正規化既約分解}

一入力一出力離散時間系の正規化既約分解は, 原理的 には以下のように多項式スペクトル分解を行うことに よって可能である. $n$ 次の系が既約な伝達関数

$$
P_{\mathrm{d}}(z)=\frac{b_{n} z^{n}+b_{n-1} z^{n-1}+\cdots+b_{0}}{z^{n}+a_{n-1} z^{n-1}+\cdots+a_{0}}=: \frac{P_{\mathrm{d} N}(z)}{P_{\mathrm{d} D}(z)}
$$

で与えられたとし， $M_{\mathrm{d} D}(z)$ を以下の多項式スペクトル 因子とする。

$$
\begin{aligned}
& M_{\mathrm{d} D}(z) M_{\mathrm{d} D}(1 / z) \\
& \quad=P_{\mathrm{d} N}(z) P_{\mathrm{d} N}(1 / z)+P_{\mathrm{d} D}(z) P_{\mathrm{d} D}(1 / z)
\end{aligned}
$$

$\ell$ を適切な非負の整数とすると, $z^{\ell} M_{\mathrm{d} D}(z)$ は $n$ 次の 多項式となり，これを改めて $M_{\mathrm{d} D}(z)$ と扔くことにより，

$$
\begin{array}{r}
M_{\mathrm{d} D}(z)=m_{n} z^{n}+m_{n-1} z^{n-1}+\cdots+m_{0} \\
\left(m_{n} \neq 0\right)
\end{array}
$$

と書け，これを用いると， $P_{\mathrm{d}}(z)$ の正規化既約因子は，

$$
\begin{aligned}
& { }^{1} N_{\mathrm{d}}(z), \quad M_{\mathrm{d}}(z) \quad \text { は } \quad \mathcal{R H}_{\infty} \text { に属し，かつ， } \\
& N_{\mathrm{d}}(z) N_{\mathrm{d}}(1 / z)+M_{\mathrm{d}}(z) M_{\mathrm{d}}(1 / z)=1 \text {. }
\end{aligned}
$$

$N_{\mathrm{d}}(z)=P_{\mathrm{d} N}(z) / M_{\mathrm{d} D}(z), M_{\mathrm{d}}(z)=P_{\mathrm{d} D}(z) / M_{\mathrm{d} D}(z)$ と なる.よって，(2) 式の多項式スペクトル分解を精度保 証付きで行えれば, 正規化既約分解が精度保証付きで得 られる。

連続時間系の正規化既約分解を求める際にも今述べた ように, 多項式スペクトル分解に帰着させ, 多項式スペ クトル分解を精度保証付きで行うことにより, 正規化既 約因子を精度保証付きで計算可能であった。ささらに，平 均的な計算コストを低減させつつ, 精度を保証するとい う目的のために, 通常の数值計算を併用するアプローチ が提案されている $[2]$. そこでは，まず計算コストの低い， 通常の数值計算を用いて計算を行い，その結果の精度を Kharitonov の定理 [4] およびKrawczyk-Moore 法 [7] 用いて厳密に精度保証付きで評価し，十分な精度がある と判断されたときには, 通常の数值計算の結果を以降の 計算に使用する。そうでない場合には，最初から時間を かけて精度保証付き計算を行う。

離散時間系の場合は, Kharitonovの定理に対応する 結果も得られてはいるが (たとえば, [6])，限定的で以 下のような問題点がある.

- 調べるべき端点多項式の数が, 区間多項式の次数が 増えるに従って増える（計算時間の増大）.

- 区間多項式の係数の範囲そのものではなく，それら を組み合わせたものの範囲に関し，条件が述べら れている（保守性の増大により, 厳密計算の頻度の 増加).

・調ベるべき多項式の係数に三角関数が現れる（精度 保証が困難になる）。

すなわち, 通常の数值計算アルゴリズムと精度保証付き 計算を組み合わせたアルゴリズムの構築は, 連続時間系 と比較すると難しくなっている。

そこで，本速報では，連続時間の多項式スペクトル分 解アルゴリズムを採用する,「離散時間の精度保証付き正 規化既約分解アルゴリズム」を提案する。これは, 離散 時間系 $P_{\mathrm{d}}(z)$ の正規化既約因子が, $P_{\mathrm{d}}(z)$ を双一次変換 して得られる連続時間系 $P_{\mathrm{c}}(s):=P_{\mathrm{d}}\left(\frac{1+s}{1-s}\right)$ の正規化既 約因子 $N_{\mathrm{c}}(s), M_{\mathrm{c}}(s)$ を双一次変換したもの

$$
N_{\mathrm{d}}(z):=N_{\mathrm{c}}\left(\frac{z-1}{z+1}\right), M_{\mathrm{d}}(z):=M_{\mathrm{c}}\left(\frac{z-1}{z+1}\right)
$$

と一致するという結果を利用している (Fig. 1参照)。こ れにより，効率的な連続時間のアルゴリズムを利用する ことが可能となる.

ここで，以下のことに留意する。

- 離散時間系のプラント $P_{\mathrm{d}}(z)$ の係数が有理数として 与えられたとき, Maple などの数式処理システムを 用いれば，双一次変換により得られる連続時間系の プラント $P_{\mathrm{c}}(s)$ の係数は有理数として厳密に求まる.

- 双一次変換により, 連続時間系の正規化既約因子 $N_{\mathrm{c}}(s), M_{\mathrm{c}}(s)$ の係数と離散時間系の正規化既約因 
子 $N_{\mathrm{d}}(z), M_{\mathrm{d}}(z)$ のそれとは簡単な一次変換の関係 付けがされる。とくに， $N_{\mathrm{c}}(s)$ (または $\left.M_{\mathrm{c}}(s)\right)$ の 分母の係数が区間として求まっている場合, 区間演 算を用いることにより $M_{\mathrm{d} D}(z)$ の係数も区間として 簡単に求まる.

・ 以上のことおよび, $N_{\mathrm{c}}(s)$ (または $\left.M_{\mathrm{c}}(s)\right)$ の分母の 係数が精度保証付きで求められることより, $M_{\mathrm{d} D}(z)$ の係数も精度保証付きで求められることがいえる.

\section{2 最適追従性能の表現}

前項で $M_{\mathrm{d} D}(z)$ の係数 $m_{k}$ の值が精度保証付きで計算 できることがわかった. 本項では, $J_{\mathrm{d}}^{\star}$ が $m_{k}$ の有理式と して表現でき，その結果， $J_{\mathrm{d}}^{\star}$ 精度保証付きで計算する ことが可能であることを述べる。まず， $M_{\mathrm{d} D}(z) を(3)$ 式で表わした場合, 以下のような表現が得られる.

【定理 2】 $\mathcal{H}_{2}$ 追従制御問題の評価関数の最適值は,

$$
J_{\mathrm{d}}^{\star}=\operatorname{tr}\left\{B_{\mathrm{n} 1}^{*} L_{\mathrm{o}} B_{\mathrm{n} 1}\right\}+\operatorname{tr}\left\{B_{\mathrm{n} 2}^{*} L_{\mathrm{o}} B_{\mathrm{n} 2}\right\}
$$

と書くことができる。ただし，

$$
\begin{aligned}
& A_{\mathrm{n}}=\left[\begin{array}{cccccc}
-m_{n-1} / m_{n} & 1 & 0 & \cdots & 0 & 0 \\
-m_{n-2} / m_{n} & 0 & 1 & \cdots & 0 & 0 \\
\vdots & & & \ddots & \ddots & \vdots \\
-m_{1} / m_{n} & 0 & 0 & \cdots & 0 & 1 \\
-m_{0} / m_{n} & 0 & 0 & \cdots & 0 & 0
\end{array}\right] \\
& B_{\mathrm{n} 1}=\left[\begin{array}{c}
b_{n}-m_{n} b_{\mathrm{sum}} / m_{\mathrm{sum}} \\
b_{n}+b_{n-1}-\left(m_{n}+m_{n-1}\right) b_{\mathrm{sum}} / m_{\mathrm{sum}} \\
\vdots \\
\sum_{j=2}^{n} b_{j}-\left(\sum_{k=2}^{n} m_{k}\right) b_{\mathrm{sum}} / m_{\mathrm{sum}} \\
\sum_{j=1}^{n} b_{j}-\left(\sum_{k=1}^{n} m_{k}\right) b_{\mathrm{sum}} / m_{\mathrm{sum}}
\end{array}\right] \text {, } \\
& \begin{array}{c}
B_{\mathrm{n} 2}=\left[\begin{array}{c}
1 \\
1+a_{n-1} \\
\vdots \\
1+\sum_{i=2}^{n-1} a_{i} \\
1+\sum_{i=1}^{n-1} a_{i}
\end{array}\right], C_{\mathrm{n}}=\left[\begin{array}{llll}
\frac{1}{m_{n}} & 0 & \cdots & 0
\end{array}\right], \\
b_{\mathrm{sum}}=\sum_{j=0}^{n} b_{j}, m_{\mathrm{sum}}=\sum_{k=0}^{n} m_{k}
\end{array}
\end{aligned}
$$

であり， $L_{\mathrm{o}}$ は Lyapunov 方程式

$$
A_{\mathrm{n}}^{*} L_{\mathrm{o}} A_{\mathrm{n}}-L_{\mathrm{o}}+C_{\mathrm{n}}^{*} C_{\mathrm{n}}=0
$$

の唯一解で, $\left[\begin{array}{llll}\ell_{1} & \ell_{2} & \cdots & \ell_{n}\end{array}\right]$ を第 1 行要素とする対称な Toeplitz 行列の形をしている.
紙面の都合上, 証明は省略するが，上記の結果は， $A_{\mathrm{n}}$ 等の表現が $a_{i}, b_{j}, m_{k}$ によって陽に表わされることを示 している.すなわち， $A_{\mathrm{n}}$ 等の計算に時間がかからず，計 算時間の短縮が達成される。

$J_{\mathrm{d}}^{\star}$ が精度保証付きで計算可能であることは, 以下の ことよりわかる. (5) 式は, 係数が $A_{\mathrm{n}}, C_{\mathrm{n}}$ の要素の多項 式である， $\ell_{i}$ に関する連立一次多項式と等価であり, し たがって, 数式処理を用いて (5) 式を厳密に解くことに より， $\ell_{i}$ は $m_{k}$ の有理式で表わされる。ささらに，(4) 式 より, $J_{\mathrm{d}}^{\star} も m_{k}$ に関する有理式で書けることが示せる. 3.1 で示した通り， $m_{k}$ は精度保証付きで計算可能であ るので, $J_{\mathrm{d}}^{\star}$ も精度保証付きで計算できる.

\section{4. おわりに}

本速報では，離散時間 $\mathcal{H}_{2}$ 最適制御問題に対する精度 保証付き計算アプローチを提案した。離散時間の場合も 原理的には，連続時間の場合同様のアルゴリズムの構築 は可能ではあるが，連続時間の場合に達成されていた高 速化を用いることは難しい. 本速報では, 双一次変換が 有効に機能する部分に関してそれを利用し，連続時間の 高速アルゴリズムを有効に活用することにより効率化を 図るアプローチを提案した。

\section{参 考文 献}

[1] 管野, 原: $\mathcal{H}_{2}$ 最適追従制御設計問題の精度保証付き計算 アルゴリズム; 計測自動制御学会論文集, Vol. 43, No. 2, pp. 102-109 (2007)

[2] M. Kanno and M. C. Smith: Guaranteed accuracy computations in systems and control; Proceedings of ECC 2003 (2003)

[3] M. Kanno and M. C. Smith: Validated numerical computation of the $\mathcal{L}_{\infty}$-norm for linear dynamical systems; Journal of Symbolic Computation, Vol. 41, No. 6, pp. 697-707 (2006)

[4] 木村, 藤井, 森：ロバスト制御, コロナ社 (1994)

[5] W. Krandick and S. Rump: Special issue on validated numerical methods and computer algebra: Foreword of the guest editors; Journal of Symbolic Computation, Vol. 24, No. 6, pp. 625-626 (1997)

[6] M. Mansour, F. Kraus and B. D. O. Anderson: Strong Kharitonov theorem for discrete systems; Proceedings of the 27th IEEE CDC, pp. 106-111 (1988)

[7] 大石：精度保証付き数值計算, コロナ社 (2000) 